\title{
STRUCTURAL-DYNAMIC ORGANIZATION OF FORESTS UNDER DIFFERENT PHYSICAL-GEOGRAPHIC CONDITIONS IN PRE-BAIKAL (East Siberia)
}

\author{
Alexander Sizykh ${ }^{1 *}$, Alexander Gritsenyuk ${ }^{2}$, Alexey Shekhovtsov ${ }^{3}$ \\ I*Siberian Institute of Plants Physiology and Biochemistry of RAS SB, 664033, Irkutsk, 132 Lermontova str., Russia; \\ ${ }^{2}$ V.R. Filippov Buryat State Academy of Agriculture, 670020, Ulan-Ude, 8 Pushkina str., Russia; \\ ${ }^{3}$ V.B. Sochava Institute of Geography SB RAS, Ulan-Batorskay str., 1, Irkutsk, 664033, Russia; \\ "Corresponding Author Alexander Sizykh, e-mail: alexander.sizykh@gmail.com;
}

Received March 2020; Accepted April 2020; Published May 2020;

DOI: https://doi.org/10.31407/ijees10.217

\begin{abstract}
Revealing of structural-dynamic organization of forests under different physical-geographic conditions, of their formation peculiarities allows to forecast the vector of probable development of forest ecosystems on vast territories. Studies of forests at regional-topological level of environmental organization promotes establishment of trends of forests genesis on the background of climate changes modern vector. Due to this fact, the monitoring of forests reconstitution dynamics will allow to get express information on formation of forests coenoses in time and space. Such forests provide in many aspects the stability and the sustainability in forests ecosystems functioning of any hierarchy in different areas of Pre-Baikal and of the whole Baikal Region.
\end{abstract}

Keywords: forests, structural-dynamic organization, physical-geographic conditions, Pre-Baikal. 